\title{
Introduction: what is the current state of knowledge transfer at research institutions in Europe, what are the main challenges and why does it matter?
}

Sven H. De Cleyn and Gunter Festel

\section{THE KNOWLEDGE TRANSFER SCENE AT PUBLIC RESEARCH INSTITUTIONS}

Research institutions, including universities and others, have engaged in knowledge transfer outside their boundaries for centuries, mostly through education and scientific publications. In recent decades, they have tried to find other, more direct ways to bring new knowledge to business and society, often facilitated by a technology transfer office (TTO) or industrial liaison office (ILO). As such, research organizations have been increasingly engaging in more entrepreneurship-related activities: establishing spin-off ventures, setting up investment funds, etc. This additional role has been described as the third mission of research institutions alongside research and education (Etzkowitz, 1998).

However, TTOs most commonly adopt a technology-push or inside-out approach, where new knowledge is 'pushed' from the research institution towards third parties. Common methods applied in this regard include the sale of intellectual property (IP), licensing or creating spin-off ventures to commercialize new technologies. This technology-push approach imposes specific challenges and many research institutions struggle to derive sufficient benefits from their knowledge transfer activities, both in the short as well as the long term.

Deriving sufficient (or more) benefits from knowledge transfer is far from a trivial concern. Several hurdles can hamper the successful transfer of knowledge from research institutions to private companies (or wider still, from one research organization to another). The first important factor impeding knowledge transfer is the cultural difference between the supplying organization and the receiver. The receiver is often a commercial 
organization (for-profit company) with a very different set of objectives to the supplier. The mindset of both organizational types is so dissimilar it often leads to a difficult handover of knowledge. Secondly, the knowledge being transferred rarely comes as a final product or ready-to-use package. Tacit knowledge typically plays a crucial role in successfully applying new knowledge. However, transferring tacit knowledge is time- and resourceintensive. The third hurdle is the nature of research institutions. These organizations are typically 'engineered' to conduct research (and eventually pass on knowledge through education and scientific publications). However, they are usually not designed for frequent interactions with industry, or for engaging in other forms of knowledge transfer. Equally, a low emphasis is placed on knowledge transfer activities in the academic career path and incentive system. One last hurdle may be the main contributing factor hindering research institutions from successfully engaging in knowledge transfer activities. Many of these organizations have been around for centuries, whilst knowledge transfer activities towards business and society have only emerged in recent decades. Therefore, research institutions typically lack a tradition of and experience in these activities.

Through continuous learning and trial and error, research institutions are seeking new ways of mastering knowledge transfer in order to derive the fullest benefits from it and the process of transferring knowledge and technologies to industrial actors (and broader society) is becoming better understood. Along with increased awareness of cluster thinking that involves academic research, the role of knowledge and technology transfer in the creation of new, technology-based ventures is now recognized. However, current practices and studies still focus on traditional ways of doing this, i.e. from a technology-push orientation (Siegel et al., 2003a) such as licensing IP rights to third parties and/or the creation of spin-off ventures. This approach has proved successful in a number of domains, including biotechnology, pharmaceuticals and microelectronics. However, in other technology domains, especially in those where patents as the main mechanism to protect IP are less common, success is limited (Santoro and Bierly, 2006; Guston, 1999).

The technology-push approach has also proved unsuccessful when it comes to start-ups and small and medium-sized enterprises (SMEs). Both types of company face important challenges in gaining access to the latest knowledge, state-of-the-art technologies and research developed at research institutions (Nunes et al., 2006). SMEs manage knowledge differently from large companies, and research institutions are (often) not adapted to interact with them. While large companies are plugged into the research community or have their own in-house R\&D departments, the innovation efforts of start-ups are usually driven by small teams operating 
without a precisely defined roadmap. In essence, start-ups often lack the ' $\mathrm{R}$ ' part of the $\mathrm{R} \& \mathrm{D}$ equation (except for start-ups in domains such as biotechnology).

For most (Western) economies, SMEs are seen as the engines of economic growth and innovation. They typically account for at least $50 \%$ of employment generated in these economies and represent more than $90 \%$ of total economic activity in any region (Federation of Small Businesses (FSB), 2014; International Finance Corporation (IFC), 2012; Singh et al., 2010). Therefore, the difficulty they face in accessing the latest technologies is a real problem.

\section{KNOWLEDGE TRANSFER EMBEDDED IN OTHER PHENOMENA}

\section{The European Innovation Paradox}

The Green Paper on Innovation (European Commission, 1995) first raised the issue of a so-called European (Innovation) Paradox. According to a number of subsequent studies (e.g. Tijssen and van Wijk, 1999; Klofsten and Jones-Evans, 2000; Clarysse et al., 2002), Europe lags behind other world regions (mainly the US) when it comes to transferring research results to the market (successfully translating these results into products and services for commercial and/or societal benefit). This poor record is, among others, attributed to the more competitive US academic environment (mainly in terms of remuneration, promotion and job mobility) and legislative system; a more pronounced distinction between teachers and researchers in Europe; and the relatively predetermined academic career path in Europe that is not conducive to commercialization activities. Other studies have pointed to the strong public sector science base in the European Union (EU) coupled with poor R\&D activities in EU firms (Tijssen and van Wijk, 1999). However, a number of other studies have challenged the existence of a European Innovation Paradox (see e.g. Dosi et al., 2006).

The response of many (European) research institutions to this Innovation Paradox has been to establish a TTO with a mission to stimulate, coordinate and support the commercialization of scientific and research results. A study by De Cleyn et al. (2010) indicated that many TTOs in Europe were established in the late 1990s. These TTOs are (potentially) important actors in the Triple Helix Model, which describes the relationship between academia, business and government. The concept of the Triple Helix, referring to university-industry-government relationships, was initiated 
in the 1990s by Etzkowitz (1993). The concept reflects on the (increasing) importance of knowledge in the triadic relationship between research institutions, industry and government. The same study supports the statement that most research institutions around the globe have limited experience (less than 25 years) of organizing structural knowledge transfer via TTOs such as academic spin-offs or technology licensing.

\section{Academic Entrepreneurship and the Triple Helix}

The European Innovation Paradox, together with changes in society, has forced research institutions to rethink their role and contribution to business and society.

As mentioned earlier, one response has been the setting-up of TTOs and intensifying the attention paid to and support of academic entrepreneurship within these institutions. TTOs play an active role in commercializing Public Research Organization (PRO) research by identifying, protecting, marketing and licensing IP developed by researchers. However, in analysing the impact of such TTO activity, studies have focused more on the effectiveness of technological diffusion that used licensing rather than spin-offs as a commercialization mechanism (Siegel et al., 2003a). There are fewer studies focusing on the impact of spin-off activity and TTO engagement with start-ups and SMEs. The main outcomes of studies by Lockett and Wright (2005) and Powers and McDougall (2005) relate to the importance of TTO size and experience in relation to spin-off activity at research institutions.

Increased engagement by research institutions in the support and promotion of entrepreneurial activities is not only an internal reflex. These institutions have become increasingly aware of the context in which they operate, no longer functioning as 'ivory towers' in which new knowledge is produced and disseminated through scientific publications and education, but as important organizations embedded in a local and global ecosystem where different actors interact (the Triple Helix Model). They can play an important role in the dynamics of a region, given their ability to create knowledge, attract companies to relocate close to them and foster job creation via spin-offs (Jones-Evans et al., 1999). Additionally, PRO inventions are an important source of knowledge spillovers (Di Gregorio and Shane, 2003), potentially benefitting numerous stakeholders in a region.

\section{Technology and Knowledge Transfer}

As mentioned earlier, this book builds on prior studies that have sought to understand the models, implications and success factors of technology and 
knowledge transfer programs and organizations in research institutions as well as in corporate environments. TTOs play an important role in supporting the translation of academic knowledge into applications. With the help of TTOs, research institutions can potentially contribute to local and global economies at various levels: by developing new technologies and knowledge that provide solutions to the challenges faced by business and society (Etzkowitz et al., 2000); by introducing innovation and - e.g. through spin-off ventures - creating new businesses that create jobs (Jones-Evans et al., 1999); by sharing new knowledge that is beneficial to a wide range of stakeholders (other researchers, students, policymakers, companies, etc.) (Gunasekara, 2006); and even by becoming critical to an entire industry, such as pharmaceuticals, which has (at least partially) become dependent on academic research for the discovery of new drugs (Festel et al., 2011).

At a more general level, Teece (2003) has tried to understand the cost of transferring technological know-how from multinationals. Indeed, knowledge has become a key raw material for many economies. And yet, despite the rise of digital technologies, transferring knowledge from one actor to another remains challenging. Other studies have focused on technology and knowledge transfer from research institutions (e.g. Lee, 1996; Siegel et al., 2003b). In this context, a recent study by Clarysse et al. (2014) have identified a gap in the knowledge and business ecosystem, which is currently not bridged by any initiative. The flipped knowledge transfer approach (as highlighted in the contribution by De Cleyn and Gielen in this book) could help to (partially) bridge this gap.

From a more financial perspective, Bray and Lee (2000) have analysed the effect of technology and knowledge transfer on research institutions. Their study concludes that institutions may benefit more from taking equity in their spin-offs than from licensing deals. In general, equity generates a return on investment equal to licensing contracts, but equity offers the advantage of occasionally hitting the 'jackpot'. Overall, equity in spinoffs maximizes the financial return research institutions can realize from their IP.

\section{Academic Spin-Offs as a Mechanism for Knowledge Transfer}

The academic spin-off (ASO) is one of the more visible mechanisms for knowledge transfer. These new ventures are set up by research institutions in order to translate specific research results (new knowledge and/or technologies) into (commercial) application. ASOs can be established by (former) academic researchers, external entrepreneurs working with PRO technologies, and/or students (student-led spin-offs). 
ASOs have specific characteristics that distinguish them from other (technology-based) start-ups. First, ASOs face the same market risk as any other start-ups, i.e. they need to find 'product-market fit' (by selling products and/or services that the market is willing to pay for). Secondly, they face a technological risk associated with the uncertain technology and subsequent product development risk. Developing new products and services based on the latest technologies always carries an inherent risk, because these technologies may not be fully understood (yet). These two risks, common to almost every technology-based start-up, are supplemented by a third risk stemming from the non-commercial background from which the ASO originates. The founders of ASOs often have an academic track record, but lack experience in a commercial environment.

Because of these risks and the absence of a prior track record at venture level (De Coster and Butler, 2005), ASOs often have difficulties in obtaining sufficient resources including but not limited to finance. Furthermore, the absence of a prior track record and an ability to objectively assess a new venture's value and potential results in low legitimacy levels. The legitimacy of an ASO stems from the founders' prior experience and knowledge (human capital), its origins (the PRO's reputation reflects on the ASO) and the relationships the founder has built up during prior activities (social capital).

Although in no sense exclusively, this book emphasizes the role ASOs (can) play in knowledge transfer activities at research institutions around Europe and the challenges they face. In this regard, various chapters focus on how to create a framework that stimulates the creation of ASOs, how ASOs are part of an entire ecosystem around a PRO, how the ASO funding challenge can be tackled and how student-led spin-offs can contribute to an effective knowledge transfer policy.

\section{Clusters of Innovation and Economic Growth}

Last but not least, this book is embedded in the concept of (global) clusters of innovation. In recent decades, it has become clear that start-ups are a major force in creating and driving innovation to the market, thereby generating economic vitality for entire regions (Engel, 2014). Attracting startups and creating a fertile breeding ground for them to flourish, however, requires a mix of ingredients that can only be provided at a regional scale, surpassing local capacities. AnnaLee Saxenian's seminal work investigated the differences between the Boston and Silicon Valley approaches and eventually predicted the latter's dominance (Saxenian, 1994). Her work has spurred more research in this domain and, as various regions around the globe have experimented with creating successful innovation hubs or 
clusters, cluster thinking has come to dominate the discussion and content of regional economic development policy.

Clusters offer many advantages to local actors: physical proximity enables economies of scale and scope, easier access to information (including the latest academic knowledge and newly developed technologies from research institutions), proximity to specialized suppliers and customers, and reduced transaction costs, among others. In real 'clusters of innovation', intense concentrations of specific industries emerge, resulting from an ongoing process of new start-up creation and fast commercialization and adoption of new technologies (Engel, 2014; Engel and delPalacio, 2009). These clusters of innovation are characterized by mobile assets (e.g. money, people and information, including know-how and IP). Additionally, an entire service industry develops around these new startups and maturing businesses.

The concept of clusters of innovation is closely related to the Triple Helix Model, where interactions between academia, industry and government play a central role. Indeed, many clusters of innovation, including the textbook example of Silicon Valley, have at some point been initiated or accelerated by some form of government intervention. In order to fuel the creation of a cluster of innovation, several authors argue that especially the interactions between industry and academia are of critical importance. In this sense, research institutions and their TTOs play a crucial role in unlocking new knowledge and research outcomes for start-ups and other actors in a regional cluster.

\section{WHY THIS BOOK?}

The objective of this book is to provide an overview of the recent challenges research institutions in Europe are facing in technology and knowledge transfer, and to share some of the latest solutions different institutions have developed to achieve more effective and successful knowledge transfer. Most research institutions now have between 10 and 25 years of experience of knowledge and technology transfer using a structured and organized approach (often through TTOs). And yet most of them are still searching for better mechanisms to organize these activities and obtain maximal results. Major progress has been made in recent decades, in practice as well as from a research perspective. As a result, the authors felt it was time to recap what has been learnt and to look ahead at solutions for current imperfections and new challenges that will emerge. It is in this spirit that the authors have assembled case studies that illustrate the impact of knowledge transfer activities on specific regions and organizations. It is 
our hope that these examples will assist others in recognizing, supporting and enhancing opportunities to develop or improve knowledge transfer activities in their own milieus.

At the conclusion of this volume, we contextualize the key insights from these cases, and map them into the main trends and challenges in knowledge transfer from previous years and for years to come. This can lead to a better understanding of the general phenomenon of knowledge transfer from research institutions and how to optimize it in the future.

\section{REFERENCES}

Bray, M.J. and J.N. Lee (2000), 'University revenues from technology transfer: Licensing fees vs. equity positions', Journal of Business Venturing, 15 (5-6): 385-92.

Clarysse, B., N. Moray and A. Heirman (2002), 'Transferring technology by spinning off ventures: Towards an empirically based understanding of the spin-off process', Working Paper, Universiteit Gent, Faculteit Economie en Bedrijfskunde, 131: 1-32.

Clarysse, B., M. Wright, J. Bruneel and A. Mahajan (2014), 'Creating value in ecosystems: Crossing the chasm between knowledge and business ecosystems', Research Policy, 43 (7): 1164-76.

De Cleyn, S.H., R. Tietz, J. Braet and M. Schefczyck (2010), Report on the status of academic entrepreneurship in Europe: 1985-2008 (Puurs: Unibook).

De Coster, R. and C. Butler (2005), 'Assessment of proposals for new technology ventures in the UK: Characteristics of university spin-off companies', Technovation, 25 (5): 535-43.

Di Gregorio, D. and S. Shane (2003), 'Why do some universities generate more start-ups than others?', Research Policy, 32 (2): 209-27.

Dosi, G., P. Llerena and M.S. Labini (2006), 'The relationships between science, technologies and their industrial exploitation: An illustration through the myths and realities of the so-called "European Paradox"”, Research Policy, 35 (10): 1450-64.

Engel, J.S. (2014), Global clusters of innovation: Entrepreneurial engines of economic growth around the world (Cheltenham: Edward Elgar).

Engel, J.S. and I. del-Palacio (2009), 'Global networks of clusters of innovation: Accelerating the innovation process', Business Horizons, 52 (5): 493-503.

Etzkowitz, H. (1993), 'Enterprises from science: The origins of science-based regional economic development', Minerva, 31 (3): 326-60.

Etzkowitz, H. (1998), 'The norms of entrepreneurial science: Cognitive effects of the new university - industry linkages', Research Policy, 27 (8): 823-33.

Etzkowitz, H., A. Webster, C. Gebhardtand and B.R.C. Terra (2000), 'The future of the university and the university of the future: Evolution of ivory tower to entrepreneurial paradigm', Research Policy, 29 (2), 313-30.

European Commission (1995), Green Paper on Innovation (Brussels, Belgium: European Commission).

Federation of Small Businesses (FSB) (2014), 'Statistics', http://www.fsb.org.uk/ stats (accessed 27 April 2016). 
Festel, G., S.H. De Cleyn, R. Boutellier and J. Braet (2011), 'Optimizing the $\mathrm{R} \& \mathrm{D}$ process using spin-outs: Case studies from the pharmaceutical industry', Research-Technology Management, 54 (1): 32-41.

Gunasekara, C. (2006), 'Reframing the role of universities in the development of regional innovation systems', The Journal of Technology Transfer, 31 (1): $101-13$

Guston, D.H. (1999), 'Stabilizing the boundary between US politics and science: The role of the Office of Technology Transfer as a boundary organization', Social Studies of Science, 29 (1): 87-111.

International Finance Corporation (IFC) (2012), 'IFC and small and medium enterprises', http://www.ifc.org/wps/wcm/connect/277d1680486a831abec2fff995 bd23db/AM11IFC+IssueBrief_SME.pdf?MOD=AJPERES (accessed 27 April 2016).

Jones-Evans, D., M. Klofsten, E. Andersson and D. Pandya (1999), 'Creating a bridge between university and industry in small European countries: The role of the Industrial Liaison Office', $R \& D$ Management, 29 (1): 47-56.

Klofsten, M. and D. Jones-Evans (2000), 'Comparing academic entrepreneurship in Europe - the case of Sweden and Ireland', Small Business Economics, 14 (4): 299-309.

Lee, Y.S. (1996), “Technology transfer" and the research university: a search for the boundaries of university-industry collaboration', Research Policy, 25 (6): 843-63.

Lockett, A. and M. Wright (2005), 'Resources, capabilities, risk capital and the creation of university spin-out companies', Research Policy, 34 (7): 1043-57.

Nunes, M.B., F. Annansingh, B. Eaglestone and R. Wakefield (2006), 'Knowledge management issues in knowledge - intensive SMEs', Journal of Documentation, 62 (1): 101-19.

Powers, J.B. and P.P. McDougall (2005), 'University start-up formation and technology licensing with firms that go public: A resource-based view of academic entrepreneurship', Journal of Business Venturing, 20 (3): 291-311.

Santoro, M.D. and P.E. Bierly (2006), 'Facilitators of knowledge transfer in university-industry collaborations: A knowledge-based perspective', IEEE Transactions on Engineering Management, 53 (4): 495-507.

Saxenian, A.L. (1994), Regional advantage: Culture and competition in Silicon Valley and Route 128 (Cambridge, MA: Harvard University Press).

Siegel, D.S., D. Waldman and A.N. Link (2003a), 'Assessing the impact of organizational practices on the productivity of University Technology Transfer Offices: An exploratory study', Research Policy, 32 (1): 27-48.

Siegel, D. S., P. Westhead and M. Wright (2003b), 'Assessing the impact of university science parks on research productivity: Exploratory firm-level evidence from the United Kingdom', International Journal of Industrial Organization, 21 (9): 1357-69.

Singh, R.K., S.K. Garg and S.G. Deshmukh (2010), 'The competitiveness of SMEs in a globalized economy: Observations from China and India', Management Research Review, 33 (1): 54-65.

Teece, D.J. (2003), 'Capturing value from knowledge assets: The new economy, markets for know-how, and intangible assets', in D.J. Teece, Essays in technology management and policy (Singapore: World Scientific).

Teece, D.J. (1998), 'Capturing value from knowledge assets: The new economy, 
markets for know-how, and intangible assets', California Management Review, 40 (3): 55-79.

Tijssen, R.J.W. and E. van Wijk (1999), 'In search of the European Paradox: An international comparison of Europe's scientific performance and knowledge flows in information and communication technologies research', Research Policy, 28 (5): 519-43. 